Research Article

\title{
Prevalence of undiagnosed hypertension among a cohort of university workers in Nigeria
}

\author{
Grace Vincent-Onabajo*, Habiba Suleiman Mohammad, Chuka Umeonwuka
}

University of Maiduguri, Maiduguri, Borno State, Nigeria

Received: 30 May 2016

Accepted: 17 June 2016

\section{*Correspondence:}

Dr. Grace Vincent-Onabajo,

E-mail: teetoe262003@yahoo.com

Copyright: () the author(s), publisher and licensee Medip Academy. This is an open-access article distributed under the terms of the Creative Commons Attribution Non-Commercial License, which permits unrestricted non-commercial use, distribution, and reproduction in any medium, provided the original work is properly cited.

\begin{abstract}
Background: Hypertension is regarded as a silent killer especially because it may remain undiagnosed. This study examined the prevalence of undiagnosed hypertension among staff of a University in Nigeria.

Methods: A cross-sectional survey of junior and senior staff of a University in Northern Nigeria was conducted. Demographic, blood pressure, and body mass index (BMI) data were obtained using appropriate instruments. Prevalence of undiagnosed hypertension was presented as percentages while Chi-square statistic was used to assess differences in the prevalence among participants in the senior and junior cadres globally, and by gender and BMI at a significance level of $\alpha=0.05$.

Results: There were 441 participants comprising 258 (58.5\%) senior and 183 (41.5\%) junior staff while mean age of participants was $40 \pm 8.5$ years. Prevalence of undiagnosed hypertension was $36.1 \%$. Differences in the prevalence were statistically significant only between obese male senior and junior staff, and obese female senior and junior staff, with higher proportions of senior staff having undiagnosed hypertension in both cases.

Conclusions: Approximately one-third of the participants had undiagnosed hypertension with a higher prevalence among obese male and female senior staff. Institution-based hypertension prevention and awareness strategies including routine blood pressure and risk factor screening are advocated.
\end{abstract}

Keywords: Undiagnosed hypertension, Nigeria, Obesity, University, Workers

\section{INTRODUCTION}

Hypertension is relatively well known as a cause of ill health and death across the world. ${ }^{1-4}$ In spite of the increasing awareness of the consequences of hypertension however, many people are not aware of their hypertensive status and thus, do not seek care. ${ }^{5-7}$ The lack of awareness of an individual's hypertensive status is particularly deadly as the frequency and severity of the morbidity, and mortality from hypertension are more profound when it remains undiagnosed and consequently untreated.

There is a growing body of literature on undiagnosed hypertension with data from various populations and countries. ${ }^{6-8-12}$ In Nigeria, the most populous country in
Africa and the seventh most populous in the world, data on undiagnosed hypertension have mostly emanated from studies involving different occupational groups. ${ }^{13-15} \mathrm{~A}$ cursory scrutiny of the available studies on occupational groups however shows a preponderance of studies involving workers in the informal sector such as traders, drivers while data on undiagnosed hypertension among workers in formal sector such as civil servants is sparse. Issues such as a lack or low level of formal education, low income, lack of work place health screening and health care services is rife among many workers in the informal sector. It is therefore plausible that a presupposition of a possibly higher prevalence of undiagnosed among this category of workers could have resulted in the apparently greater level of attention in available literature. 
Identifying the prevalence of undiagnosed hypertension among workers in the formal sector is however also required as that would assist in understanding the gravity of the problem among this category of workers with a view of addressing it with appropriate strategies. For instance, a recent systematic review on the prevalence of hypertension among workers in West Africa showed that in spite of mandatory medical screening, which often entails blood pressure measurement, many workers in the formal sector had undiagnosed hypertension. ${ }^{16}$ In order to address the dearth in literature on prevalence of undiagnosed hypertension among workers in the formal sector in Nigeria, especially civil servants, this study was conducted. While civil servants play a very crucial role in the all-round development of any nation, those in the educational sector are directly or indirectly involved in the formal training and education of a country's future workforce, and manpower development. A healthy workforce in the educational sector will however be required to achieve these critical functions. This study therefore investigated the prevalence of undiagnosed hypertension among the staff of a government-owned University in Nigeria and also compared prevalence between staff in the senior and junior cadres. Additionally, comparisons of the prevalence of undiagnosed hypertension between the two staff groups were made based on gender, and the presence of a major modifiable risk factor of hypertension, namely, obesity.

\section{METHODS}

Study design: It's a cross-sectional descriptive survey.

Study setting: A federal government-owned University in North-Eastern Nigeria.

Participants: A convenience sample of senior and junior staff participated in this study.

\section{Inclusion criteria}

- No previous diagnosis of hypertension and/or use of anti-hypertensive medications;

- Willingness to participate in the study expressed through signing of informed consent form which was part of the study's introductory letter.

Instruments: An electronic sphygmomanometer (Model KBM-910) was used in measuring participant's blood pressure. A weighing scale (Hanson's Model) calibrated in kilograms from $0-120 \mathrm{~kg}$ was used to measure the participant's body weight while a locally fabricated wooden height meter was used for the measurement of height. All the obtained data including participants' age and gender, and occupational cadre (senior or junior cadre) were recorded on specially designed data forms.

Procedure: Approval for the study was obtained from the relevant institutional ethics committee. Participants were approached during working hours in their respective offices within the University campus. The second author (HSM) and research assistants approached prospective participants with introductory letters which provided a brief explanation of the study protocol after verbal introductions were made. The study was conducted in 2011.

Measurements: Blood pressure was measured with the cuff of the sphygmomanometer wrapped around each participant's arm approximately $2-5 \mathrm{~cm}$ above the cubital fossa and the center of the cuff was aligned with the participant's brachial artery. The sphygmomanometer was then turned on, it inflated automatically and thereafter the pressure reduced gradually until the cuff released the air completely. The reading of the blood pressure appeared on the screen of the electronic sphygmomanometer and the value was recorded on the data form. To ensure that the resting blood pressure was captured, the measurement was taken after the participants sat for at least 5 minutes without any work activity. Hypertension was classified as a systolic blood pressure equal to or greater than to $140 \mathrm{mmHg}$ and diastolic blood pressure equal to or greater than 90 mmHg. ${ }^{17}$

Height was measured with each participant in upright standing position without shoes. With the backs of the participants against the height meter, measurement of height entailed standing erect with the neck held upright, eyes looks forward, hip in neutral position and knee extended with feet slightly apart. Height was read off by the researcher standing in front of the participant, noting the corresponding level of the vertex of the head on the height meter. Measurement of weight was taken with the participants standing erect and feet slightly apart on the weighing scale without footwear or any external material that may increase the body weight of the participant. Weight was read by the examiner squatting in front of the scale to avoid error due to parallax. Body mass index (BMI) for each participant (body weight in kilograms divided by the square of height in meters) was calculated and recorded on the data forms and the World Health Organization's classification of BMI was used to categorise participants as being of normal weight (18.5$\left.24.9 \mathrm{~kg} / \mathrm{m}^{2}\right)$, being overweight $\left(25-29.9 \mathrm{~kg} / \mathrm{m}^{2}\right)$, and obese $\left(>30 \mathrm{~kg} / \mathrm{m}^{2}\right)$.

\section{Data analyses}

Descriptive statistics of frequencies, percentages, means and standard deviation were used to present the demographic, blood pressure and BMI data. Prevalence rates of undiagnosed hypertension were presented as percentages.

Chi-square statistics was used to examine the differences in prevalence of undiagnosed hypertension based on participants' occupational strata (senior and junior cadre 
staff), gender and obesity status. Level of statistical significance was set at alpha $=0.05$.

\section{RESULTS}

\section{Characteristics of participants}

A total of 441 senior and junior staff participated in the study comprising 258 (58.5\%) senior and $183(41.5 \%)$ junior staff. There were more male participants $(51.5 \%)$, and mean age and BMI was $40 \pm 8.5$ years and $26 \pm 4.9$ $\mathrm{kg} / \mathrm{m}^{2}$ respectively (Table 1 ).

Table 1: Physical characteristics of the participants.

\begin{tabular}{|ll|}
\hline Variable & Value \\
\hline Age & \\
Mean \pm SD & $40 \pm 8.5$ years \\
\hline Gender & $\mathrm{N}(\%)$ \\
Male & $227(51.5)$ \\
Female & $214(48.5)$ \\
\hline Marital status & $\mathrm{N}(\%)$ \\
Single & $83(18.8)$ \\
Married & $337(76.4)$ \\
Divorced & $6(1.4)$ \\
Widowed & $15(3.4)$ \\
\hline Body Mass Index & $\mathrm{N}(\%)$ \\
Mean \pm SD & $26 \pm 4.9 \mathrm{~kg} / \mathrm{m}^{2}$ \\
Normal weight & $167(37.9)$ \\
Overweight & $176(39.9)$ \\
Obese & $98(22.2)$ \\
\hline
\end{tabular}

Table 2: Differences in the prevalence of undiagnosed hypertension among staff by cadre and obesity.

\begin{tabular}{|c|c|c|c|}
\hline $\begin{array}{ll}\text { Characteristic } & \text { U } \\
& \end{array}$ & $\begin{array}{l}\text { Undiagnosed } \\
\text { HTN } \\
\text { N\% }\end{array}$ & $\begin{array}{l}\text { Nil } \\
\text { Undiagnosed } \\
\text { HTN }\end{array}$ & \\
\hline Senior Staff & $85(32.9)$ & $173(67.1)$ & \multirow[t]{2}{*}{2.61} \\
\hline Junior Staff & $74(40.4)$ & $109(59.6)$ & \\
\hline Male senior staff & $56(43.8)$ & $72(56.3)$ & \multirow[t]{2}{*}{0.74} \\
\hline Male junior staff & $49(49.5)$ & $50(50.5)$ & \\
\hline Female senior staff & f $29(22.3)$ & $101(77.7)$ & \multirow[t]{2}{*}{1.50} \\
\hline Male junior staff & $25(29.8)$ & $59(70.2)$ & \\
\hline $\begin{array}{l}\text { Obese male } \\
\text { senior staff }\end{array}$ & $27(60)$ & $18(40)$ & \multirow[t]{2}{*}{$20.96 *$} \\
\hline $\begin{array}{l}\text { Obese male } \\
\text { junior staff }\end{array}$ & $10(55.6)$ & $8(44.4)$ & \\
\hline $\begin{array}{l}\text { Obese female } \\
\text { senior staff }\end{array}$ & $6(31.6)$ & $13(68.4)$ & \multirow[t]{2}{*}{$7.28 *$} \\
\hline $\begin{array}{l}\text { Obese female } \\
\text { junior staff }\end{array}$ & $4(25)$ & $12(75)$ & \\
\hline
\end{tabular}

\section{Prevalence of undiagnosed hypertension}

A total of 159 participants had undiagnosed hypertension giving a prevalence of $36.1 \%$. Prevalence of undiagnosed was not significantly different between participants in the senior and junior cadre, both for the entire sample and by gender (Table 2).

Statistically significant differences in the prevalence of undiagnosed hypertension were however observed between obese male senior and junior staff, and obese female senior and junior staff with higher proportions of senior staff having undiagnosed hypertension in both cases (Table 2).

\section{DISCUSSION}

Information on the prevalence of undiagnosed hypertension in specific populations and groups is very essential in planning effective awareness strategies that can be tailored to the peculiarities of each population and group. This study investigated the prevalence of undiagnosed hypertension among staff in junior and senior cadres at a University in Nigeria and observed that $36.1 \%$, constituting approximately 1 in every 3 university staff surveyed, had undiagnosed hypertension.

The prevalence of undiagnosed hypertension in this study is lower than rates reported among workers in the informal sector such as commercial bus and traders in different regions of Nigeria. ${ }^{13-15}$ A likely explanation for the lower prevalence of undiagnosed hypertension in this present study compared to the above cited studies could be the higher level of education of the study participants (being staff of a University) which could result in better health-seeking behaviour. This behaviour coupled with the availability of workplace health care facilities which would easily afford workers opportunities for regular medical checks could also play a role in the lower prevalence of undiagnosed hypertension. The prevalence in this present study is however higher than the $25 \%$ reported in a study of bank workers in Nigeria. ${ }^{19}$ This observation is somewhat unexpected especially as the setting of the present study, like other Universities in Nigeria, has a functional health center/clinic that caters for the needs of staff (and students), a situation that not exist in banks. However, the $65.3 \%$ prevalence of undiagnosed hypertension reported in a study of hospital workers in Bayelsa, Nigeria appear to show that proximity and unrestricted access to healthcare facilities does not necessarily translate to utilization of such facilities to facilitate detection and diagnosis of a disease as deadly as hypertension. ${ }^{20}$

This study sought to identify whether the prevalence of undiagnosed hypertension would significantly differ between participants in the senior cadre and those in junior cadre but found no difference between these two groups in the absolute sample. While level of education and income are two of the most glaring distinguishing 
characteristics between staff in the senior and junior occupational cadres, it would appear from the findings of this study that these two characteristics did not impact on awareness of one's hypertensive status. It is however important to note that statistically significant differences were observed when BMI-specific differences were investigated between participants in senior and junior cadre. The results showed a significant difference in the prevalence of undiagnosed hypertension between obese male senior staff and obese male junior staff, and between obese female senior staff and obese female junior staff. Furthermore, prevalence of undiagnosed hypertension was higher among participants who were senior staff in each case. The implication of these findings is that a significantly higher proportion of persons in the senior cadre with an established and modifiable risk factor of hypertension, that is obesity, were not aware of their hypertensive status. It therefore appears, though paradoxically, that more participants at increased risk of hypertension, who ought to be knowledgeable due to their education level, and who could relatively more easily afford and access medical services due to their comparatively higher income, were less aware that they were hypertensive.

Comparison of the findings of this study with other studies involving university staff in Nigeria was almost impossible as there appeared to be a scarcity of studies on prevalence of undiagnosed hypertension among staff of Universities in Nigeria. Rather, available studies focused on diagnosed hypertension while one study that also examined level of awareness of hypertension diagnosis among its participants involved both staff and students. ${ }^{21,22}$ There is therefore a need for further studies on prevalence of undiagnosed hypertension among staff of Universities in different regions of Nigeria. Future studies on effective strategies capable of appreciably reducing not only the prevalence of undiagnosed hypertension, but also the prevalence of hypertension among University workforce is also urgently required.

An important limitation of this study is the nonprobability sampling technique utilized in recruiting participants which could have resulted in selection bias and negatively affected the generalizability of findings.

\section{CONCLUSION}

The outcome of this study suggests that institution-based and institution-driven policies on mandatory routine medical checks including blood pressure and weight measurements would be beneficial for early detection of hypertension and its risk factors such as obesity. Regular health education that would engender awareness and prevention of the risk factors of hypertension should also be emphasized.

\section{Funding: No funding sources} Conflict of interest: None declared

Ethical approval: The study was approved by the Institutional Ethics Committee

\section{REFERENCES}

1. Oliveria SA, Chen RS, McCarthy BD, Davis CC, Hill MN. Hypertension knowledge, awareness, and attitudes in a hypertensive population. J Gen Intern Med. 2005;20:219-25.

2. Abdullahi AZ, Amzat J. Knowledge of hypertension among the staff of University of Ibadan, Nigeria. Journal of Public Health and Epidemiology. 2011;3:204-9.

3. Kusuma YS. Perceptions on hypertension among migrants in Delhi, India: a qualitative study. BMC Public Health. 2009;9:267.

4. Yoon S, Fonarow G. Recent trends in the prevalence of high blood pressure and its treatment and control, 1999-2008. CDC. 2010.

5. Centers for Disease Control and Prevention (CDC). Vital signs: Awareness and treatment of uncontrolled hypertension among adults - United States, 2003-2010. MMWR. 201;61:703-9.

6. Chow CK, Teo KK, Rangarajan S, Islam S, Gupta $\mathrm{R}$, Avezum A, et al. Prevalence, awareness, treatment, and control of hypertension in rural and urban communities in high, middl, and low-income countries. JAMA. 2013;310:959-68.

7. World Health Organization. Nigerian wake up to hypertension. Bulletin of the World Health Organization 2013;91:242-3. Accessed at: www.who.int/bulletin/volumes/91/4/13-020413/en/ on 30/4/2016.

8. Atakite F, Erquo S, Kaptoge S, Echouffo-Tcheugui JB, Kengne AP. Burden of undiagnosed hypertension in Sub-Saharan Africa. A systematic review and meta-analysis. Hypertension. 2014;114.04394.

9. Dolatabadi AA, Motamedi M, Hatamabadi H, Alimohammadi H. Prevalence of undiagnosed hypertension in the emergency department. Trauma. $2014 ; 19$.

10. Johnson HM, Thorpe CT, Bartels CM, Schumacher JR, Palta M, Pandhi $\mathrm{N}$ et al. Undiagnosed hypertension among young adults with regular primary care use. J Hypertens. 2014;32:65-74.

11. Zoeliner J, Thomson JL, Landry AS, AndersonLewis C, Connell C, Fontenot Molaison E et al. Improvements in blood pressure among undiagnosed hypertensive participants in a community-based lifestyle interventions, Mississipi, 2010. Pre Chronic Dis. 2014;11.

12. Shukla AN, Madan T, Thakkar BM, Parmar MM, Shah KH. Prevalence and predictors of undiagnosed hypertension in an apparently healthy Western Indian population. Advances in Epidemiology 2015. Available at:http://dx.dpi.org/10.1155/2015/649184.

13. Ulasi II, Ijoma CK, Onwubere BJ, Arodiwe E, Onodugo O, Okafor C. High prevalence and low awareness of hypertension in a market population in Enugu, Nigeria. Int J Hypertens. 2011.

14. Fatiu A, Abubakr S, Muzamil H, Aderoju G, Funmilayo O, Bola O, Adewale A. Undiagnosed 
hypertension and proteinuria in a market population in Ile-Ife, Nigeria. Arab J Nephrol Transplant. 2011;4:141-6.

15. Erhiano EE, Igbokwe VU, El-khashab MM, Okolo RU, Awosan KJ. Prevalence of hypertension among commercial bus drivers in Sokoto, Sokoto State, Nigeria. Journal of Medicine and Medical Sciences. 2015;2:34-9.

16. Bosu WK. The prevalence, awareness, and control of hypertension among workers in West Africa; a systematic review. Glob Health Action. 2015;8.

17. Chobanian AV, Bakris GL, Black HR, Cushman WC, Green LA, Izzo JL Jr et al. Joint national committee on prevention, detection, evaluation, and treatment of high blood pressure. National Heart, Lung, and Blood Institute. National High Blood Pressure Education Program Coordinating Committee. Seventh report of the Joint National Committee on Prevention, Detection, Evaluation, and Treatment of High Blood Pressure. Hypertension. 2003;42:1206-52.

18. World Health Organization. Obesity: preventing and managing the global epidemic. Report of a WHO consultation on obesity. Geneva; 1997.
19. Diwe KC, Enwere OO, Uwakwe KA, Duru CB, Chineke HN. Prevalence and awareness of hypertension and associated factors among bank workers in Owerri, Nigeria. IJBMR. 2015;4:1-7.

20. Egbi OG, Rotifa S, Jumbo J. Prevalence of hypertension and its correlates among employees of a tertiary hospital in Yenagoa, Nigeria. Annals of African Medicine. 2015;14:8-17.

21. Emerole CO, Aguwa E, Onwasigwe CN, Nwakoby BAN. Cardiac risk indices of staff of Federal University of Technology Owerri, Imo state, Nigeria. Tanzan Health Res Bull. 2007;9:132-5.

22. Chinyere OI, Mwuese UP, Ara BI. Prevalence and awareness of hypertension amongst staff and students of a tertiary institution in Nigeria. Glo Adv Res J Med Med Sci. 2015;4;061-6.

Cite this article as: Vincent-Onabajo G, Mohammad HS, Umeonwuka C. Prevalence of undiagnosed hypertension among a cohort of university workers in Nigeria. Int J Community Med Public Health 2016;3:1963-7. 